\title{
Recomendações para elaboração de orçamento de obras de reabilitação de edifícios habitacionais
}

\author{
Guidelines for estimating costs of residential building \\ rehabilitation projects
}

\section{Christiano Romanholo Marques de Jesus Mércia Maria Semensato Bottura de Barros}

\section{Resumo

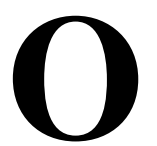

segmento de reabilitação de edifícios residenciais no Brasil vem se desenvolvendo lentamente, seja por meio de programas habitacionais geridos pelo Estado, seja de maneira ainda tímida pelo mercado imobiliário privado. Entretanto, a exemplo de muitos países europeus, essa atividade tende a se intensificar com o passar dos anos e exigirá conhecimentos específicos hoje não consolidados. O processo de produção de um empreendimento de reabilitação é bastante distinto do de um edifício novo, demandando o desenvolvimento de novos parâmetros tecnológicos, de gestão e de custos. Com base neste contexto, o presente trabalho tem como objetivo propor recomendações para elaboração de orçamento de obras de reabilitação de edifícios para uso habitacional. $\mathrm{O}$ trabalho é baseado num estudo minucioso dos custos envolvidos na produção de cinco empreendimentos de reabilitação habitacional realizados na cidade de São Paulo, para os quais foram elaborados os orçamentos detalhados e a curva ABC. A análise dos custos dos empreendimentos permitiu estabelecer um intervalo de participação percentual do custo de produção dos subsistemas do edifício no custo total da obra de reabilitação.

Christiano Romanholo Marques de Jesus Caixa Econômica Federal Av. Magalhães Neto, 1529, Pituba, Salvador - BA - Brasil CEP 41810-012

Tel.: (71) 3402-2841

E-mail: christiano.jesus@caixa.gov.br

Mércia Maria Semensato Bottura de Barros Departamento de Engenharia de Construção Civil, Escola Politécnica Universidade de São Paulo Av. Prof. Almeida Prado, 83, Travessa

2, Cidade Universitária São Paulo - SP - Brasil CEP 05508-900 Tel.: (11) 3091-5790 E-mail: mercia.barros@poli.usp.br

Recebido em 03/11/10 Aceito em 24/05/11
Palavras-chave: Reabilitação de edifícios. Custos de produção. Orçamento. Habitação de interesse social. Empreendimentos de edifícios residenciais.

\section{Abstract}

The segment of residential building rehabilitation has been growing slowly, due to both housing programs led by the government, and, in a much smaller scale, the private housing market. However, similarly to what has happened in many European countries, this activity is likely to increase over the years and will require expertise not yet available. The production process of a rehabilitation project is substantially different from that of new building, demanding the development of new parameters in technology, management and costs.

Considering this context, the aim of this study is to propose guidelines for estimating costs of building rehabilitation projects for residential use. The study is based on a detailed study of the costs involved in the production of five housing rehabilitation projects carried out in São Paulo, for which detailed cost estimates and an ABC curves were prepared. Based on the cost analysis of the projects, $a$ range of percentage shares of the production cost of subsystems in relation to total building rehabilitation costs was proposed.

Keywords: Building rehabilitation. Production costs. Cost estimating. Social housing. Residential building projects. 


\section{Introdução}

Os centros urbanos de grandes cidades vêm sofrendo, desde muito tempo, um processo de esvaziamento dos edifícios, seja por sua degradação, por sua obsolescência funcional e, mais recentemente, por sua obsolescência energética, principalmente em função das atuais exigências de sustentabilidade ambiental. Reverter esse processo tem exigido diferentes tipos de intervenção, conhecidos em seu conjunto como reabilitação.

Em países europeus, entre os quais França, Itália, Noruega, Reino Unido e Suécia, importantes investimentos visando à recuperação de edifícios e de seu entorno têm sido realizados desde a década de 70. Nesses países, os recursos destinados à reabilitação equiparam-se aos destinados a construções novas (EUROCONSTRUCT, 2003).

Além disso, a pesquisa sobre o tema é intensa, sendo inúmeros os trabalhos publicados. Por exemplo, o trabalho de Anjaneyulu (2003), nos Estados Unidos apresenta estudos de caso que fundamentam a análise de custos de reabilitação de edifícios após a implementação, em Detroit, de novos códigos de obra específicos para esse tipo de empreendimento. Segundo o mesmo autor, o uso de tais códigos implicou redução de $22 \%$ do custo de reabilitação, quando comparado com a utilização do código voltado a obras novas. Forest (1999) também afirma que em apenas um ano após a implantação de códigos de obra especificamente destinados à reabilitação, o número de empreendimentos aumentou $60 \%$.

Também nos Estados Unidos o tema é frequente. Cita-se, por exemplo, o trabalho de Anjaneyulu (2003), que apresenta estudos de caso que fundamentam a análise de custos de reabilitação de edifícios após a implementação, em Detroit, de novos códigos de obra específicos para esse tipo de empreendimento. Segundo o autor, o uso de tais códigos implicou redução de $22 \%$ do custo de reabilitação, quando comparado com a utilização do código voltado a obras novas. Forest (1999) também afirma que em apenas 1 ano após a implantação de códigos de obra especificamente destinados à reabilitação, o número de empreendimentos aumentou $60 \%$.

A necessidade de reabilitação está presente também no Brasil. Segundo dados dos trabalhos de Bomfim (2004) e Devecchi (2010), há um processo contínuo de esvaziamento do centro das grandes cidades brasileiras, agravado com o passar dos anos. Isso tem ocasionado subutilização da infraestrutura instalada, bem como degradação dos patrimônios histórico, artístico e arquitetônico da cidade.

A reabilitação desse importante parque imobiliário tem sido discutida tanto pelo Estado como pelo meio técnico e esperada por toda a sociedade, pois, como bem destaca Cambiaghi (2010), o aproveitamento desses edifícios é uma das formas de contribuir para a diminuição do déficit habitacional.

Portanto, a reabilitação de edifícios no Brasil pode ser considerada como um processo necessário e irreversível; no entanto, programas relacionados à intervenção em edifícios em áreas centrais têm sido timidamente desenvolvidos. $\mathrm{O}$ mais expressivo foi o Programa de Arrendamento Residencial (PAR), lançado em 1999 pelo Governo Federal, com a finalidade de prover habitação a famílias com renda mensal entre 3 e 6 salários mínimos e que tinha uma de suas linhas de financiamento destinada à habitação a partir da reabilitação de edifícios, denominada de PARReforma. Mesmo havendo uma prospecção para cerca de 7.500 unidades, somente cerca de 1.500 foram construídas durante a vigência do projeto (CAIXA..., 2011).

O setor privado, por sua vez, não tem investido sistemicamente na reabilitação, ainda que existam experiências positivas, como as relatadas em “'Cirurgia plástica' chega a dobrar preços de prédios" (BRANCATELLI, 2010). Destaca-se, porém, que tais experiências, além de pontuais, têm envolvido empreendimentos com elevados preços de comercialização. Quando se trata de reabilitação visando à habitação de interesse social, o risco envolvido na atividade aumenta e pode resultar em sérios prejuízos financeiros à empresa, afastando-a desse tipo de empreendimento, como bem mostram os trabalhos de Yolle Neto (2006) e os relatórios do projeto REABILITA (2007).

Os riscos e as dificuldades para a realização da reabilitação podem estar associados a diversos fatores. Desconhecimento técnico sobre as características inerentes a obras de reabilitação, inexistência de métodos para diagnóstico das condições físicas do edifício existente, inadequação das tecnologias tradicionais à condição da reabilitação, dificuldade de atendimento à legislação vigente e ausência de indicadores que permitam estimar seus custos com precisão são alguns deles.

Este último aspecto merece destaque, pois, ao se falar em reabilitação, surge o questionamento: o que seria melhor? Demolir o edifício e construir 
um novo ou reabilitá-lo? O artigo "Construir ou Reformar?" apresenta essa temática (CARVALHO, 2005).

Vários são os aspectos que influenciam na tomada de decisão, como valor de mercado do edifício, sua finalidade depois de reabilitado, exigências ambientais e de sustentabilidade, necessidade de preservação do patrimônio e, naturalmente, os custos envolvidos. Surge, então, nova pergunta: como estimar rapidamente tais custos?

Como bem afirmam Leeuwen, Vries e Oetelaar (2000), a natureza de um projeto de reabilitação difere totalmente da de uma obra nova. Portanto, os parâmetros usualmente utilizados para estimativas de custo delas não podem ser diretamente utilizados.

As dificuldades para estimativa de custo ficam claras quando a Caixa Econômica Federal, principal órgão financiador da reabilitação de edifícios no país, não possui parâmetros específicos para projeto e orçamento dessas obras, dificultando qualquer análise de viabilidade do empreendimento.

No que se refere ao orçamento desse tipo de empreendimento, o principal referencial disponível é o Sistema de Preços, Custos e Índices (SIPCI). Trata-se de um software cuja base de dados é o Sistema Nacional de Pesquisa de Custos e Índices da Construção Civil (SINAPI), utilizado para a elaboração de orçamentos de qualquer tipo de empreendimento (CAIXA..., 2006), cuja base de dados decorre de obras novas.

Não apenas os aspectos de projeto são distintos entre a obra nova e a de reabilitação. Como destaca Yolle Neto (2006), esta tem lógica de produção distinta da lógica daquela: não se começa construindo, e sim desconstruindo. Munhoz e Souza (2009), por sua vez, ao analisarem obras de reforma, principalmente aquelas realizadas sob autogestão, concluem que as indefinições do projeto influenciam fortemente na produtividade das diferentes atividades. Além disso, destacam que no ambiente de reformas há maior complexidade na logística e administração do canteiro de obras, o que também resulta em queda de produtividade. Dadas as distintas características das atividades entre obras de reabilitação e novas, fica evidente a dificuldade de elaboração de estimativas preliminares e do orçamento da obra de reabilitação, como destacado por Marques de Jesus e Barros (2007), ao afirmarem que em obras de reabilitação, dadas suas incertezas, o levantamento de quantitativos torna-se um processo bastante complexo.
Apesar dessas dificuldades, autores como Assumpção e Fugazza (2000), Kern, Formiga e Formoso (2004) e Goldman (2004) são unânimes em afirmar a importância do orçamento como ferramenta para planejamento e acompanhamento dos custos de construção.

Portanto, urge o desenvolvimento de parâmetros para essas obras, os quais podem ser determinados a partir de experiências realizadas. É, pois, nesse contexto que se insere este trabalho, cujo objetivo é analisar as obras de reabilitação no que se refere a sua composição de custos e, assim, apresentar recomendações que possam subsidiar a estimativa dos custos de produção para esses empreendimentos.

Para tanto, o trabalho é apoiado por uma revisão bibliográfica em que se identificaram os principais métodos para a elaboração de orçamentos e por um estudo de caso envolvendo cinco obras reabilitadas para habitação, para as quais o orçamento foi realizado. A análise dos resultados, ainda que limitada pelo reduzido tamanho da amostra, possibilitou formular algumas recomendações com vistas a subsidiar a atividade de orçamento em empreendimentos futuros. Trata-se, pois, de uma primeira aproximação, cuja precisão poderá ser melhorada com a realização de novos trabalhos, que poderão utilizar os parâmetros aqui apresentados como referência inicial.

\section{Um conceito para reabilitação de edifícios}

Abordar o tema orçamento de obras de reabilitação exige precisar o significado de reabilitação. Retrofit, reforma, reabilitação, entre outros, são termos usados indistintamente pela academia, pelo meio técnico e pela mídia - especializada ou não referindo-se a intervenções para recuperar ou implementar funções em edifícios. Entre esses termos, reabilitação tem sido o mais utilizado para identificar intervenções em áreas urbanas ou em edifícios, uma vez que os demais tratam, usualmente, de intervenções mais localizadas, relativas a uma parte do edifício, como bem demonstram os conceitos de retrofit e manutenção, sintetizados por Marques de Jesus (2008) a partir de extensa revisão bibliográfica:

Retrofit é a troca ou substituição de componentes ou subsistemas específicos de um edificio que se tornaram inadequados ou obsoletos, seja pelo passar do tempo, ou em função da evolução tecnológica ou de novas necessidades dos usuários. 
Manutenção é o conjunto de atividades a serem realizadas em uma edificação, ou em uma sua parte, de forma preventiva ou corretiva, que visam conservar ou recuperar a sua capacidade funcional, bem como atender às necessidades de segurança dos usuários.

Por sua vez, Maricato (2000) procura distinguir os termos "reforma" e "reabilitação" de acordo com o grau de complexidade dos serviços, afirmando que as empresas que trabalham com reforma são menores e mais ligadas ao trabalho artesanal, quando comparadas às que trabalham em obras de reabilitação. Nessas, as intervenções ocorrem no edifício com um todo, e exigem uma forma de gestão da obra mais especializada.

Marques de Jesus (2008) destaca, ainda, que ao se tratar da reabilitação de edifícios são possíveis duas abordagens: edifícios que pertencem ao patrimônio histórico, associados os serviços de restauro (BCSD PORTUGAL, 2011); ou aqueles de uso corrente, relacionados, por exemplo, aos serviços de reforma, retrofit (ASMUSSEN, 2004; CIANCIARDI, MONTEIRO; BRUNA, 2004) e manutenção (AGUIAR; CABRITA; APPLETON, 2002). Para aquele autor, todos esses serviços estariam inseridos num contexto mais amplo (Figura 1).

O termo reabilitação de edifícios, na língua inglesa, aparece como refurbishment, de origem britânica (EGBU; YOUNG; TORRANCE, 1997; MANSFIELD, 2002); e rehabilitation, de origem norte-americana (SECRETARY..., 1992; INTERNATIONAL..., 2003). Na língua portuguesa, é tratado por Aguiar, Cabrita e Appleton (2002).
Sistematizando os conceitos apresentados por esses e outros autores, Marques de Jesus (2008) propõe o conceito assumido neste trabalho:

Reabilitação de edifícios é uma ação que pode envolver atividades de restauro, manutenção, alteração, retrofit, reparo ou reforma visando dotar o edifício de atributos econômicos ou funcionais equivalentes aos exigidos a um edifício novo para o mesmo fim.

Tal ação pode ocorrer com diferentes graus de intervenção, desde uma simples remoção ou aplicação de novos elementos até a promoção de grandes alterações, que interferem na maior parte do edifício (MARQUES DE JESUS, 2008).

\section{Métodos para orçamento de obras de reabilitação}

Elaborar o orçamento de um empreendimento, segundo Giamusso (1991), é determinar ou prever os custos para sua realização, antes de sua execução.

Seja qual for o tipo de orçamento - estudo de viabilidade ou final -, sua elaboração pressupõe a existência de parâmetros, os quais estão relativamente bem consolidados para obras novas. Fontes como a Tabela de Composição de Preços para Orçamentos (PINI, 2009), em sua $13^{a}$ edição, ou mesmo alguns softwares desenvolvidos para orçamento e planejamento de obras auxiliam em sua elaboração, estabelecendo parâmetros de consumo de materiais, de equipamentos e de mão de obra. Além disso, o histórico das obras de determinada empresa permite-lhe criar seu próprio banco de dados.

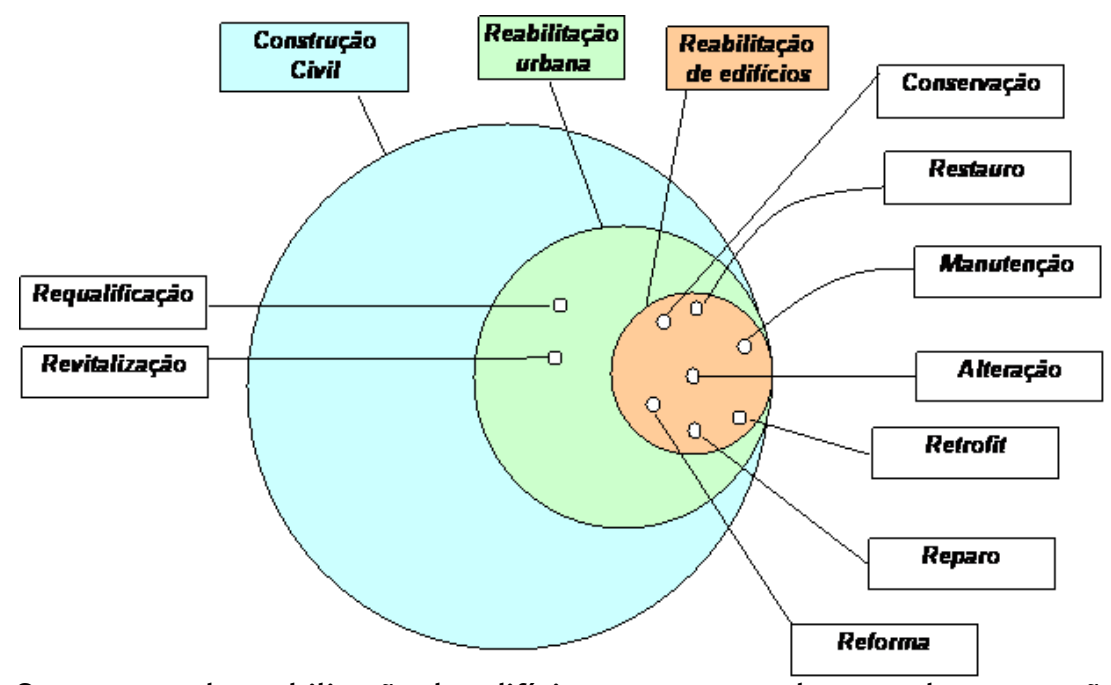

Figura 1 - 0 segmento de reabilitação de edifícios no contexto do setor da construção civil e as atividades por ele compreendidas

Fonte: Marques de Jesus (2008). 
As análises de Yolle Neto (2006), feitas para um estudo de caso de reabilitação, mostram que não é adequado utilizar índices obtidos a partir de obras novas para orçar as de reabilitação. Por exemplo, nas obras de reabilitação tem-se a atividade de demolição de partes do edifício, gerando-se, logo em seu início, grande volume de material a ser removido, cujas condições para retirada são distintas das de uma obra nova. Para aquelas, sobretudo em zonas centrais, há limitações de espaço, de horário, de acesso, entre outras (REABILITA, 2007). Além disso, como foi constatado nos estudos de caso a seguir apresentados, é comum a demolição ter longa duração, misturando-se às atividades de substituição e de construção de novos elementos. Esse fluxo de atividades gera custos, que deverão ser considerados no orçamento da obra de reabilitação; no entanto, poucos são os parâmetros para sua correta avaliação.

A Tabela de Custos de Manutenção e Reformas (PINI, 2006) - para serviços de manutenção, reformas, ampliações e reparos de edificações - é um conjunto de parâmetros disponível. Nela, a composição de custos é apresentada tal como a de uma obra nova, porém com produtividade reduzida usualmente à metade.

Tendo em vista a inexistência de parâmetros mais precisos, essa tabela pode servir para uma primeira aproximação; no entanto, como destacado por
Marchiori e Souza (2004), as produtividades variam muito de acordo com as especificidades de cada obra, e a utilização de coeficientes médios de produtividade pode conduzir a imprecisões na elaboração de orçamentos. Se para obras novas a produtividade varia, mais ainda variará para as de reabilitação, exigindo, por isso, trabalhos voltados à determinação desses coeficientes, tais como o apresentado por Munhoz e Souza (2009).

No entanto, para que se estabeleça o custo final do empreendimento, um método de elaboração de orçamento deve estar associado a esses parâmetros.

Atualmente, o método que considera a composição de custos diretos e indiretos de cada atividade ou serviço é o que tem sido mais empregado, sendo por isso usualmente denominado método tradicional. Nesse método, cujas atividades estão sistematizadas na Figura 2, há uma etapa denominada estudo das condicionantes, que envolve amplo conhecimento e domínio dos projetos e documentos técnicos; com esses dados, passa-se à fase de composição dos custos. Para tanto, faz-se necessário, inicialmente, identificar os serviços e realizar o levantamento de seus quantitativos; com isso, pode-se partir para a apropriação dos custos diretos e indiretos, aos quais devem ser acrescidos os impostos e lucro pretendido para resultar o custo final.

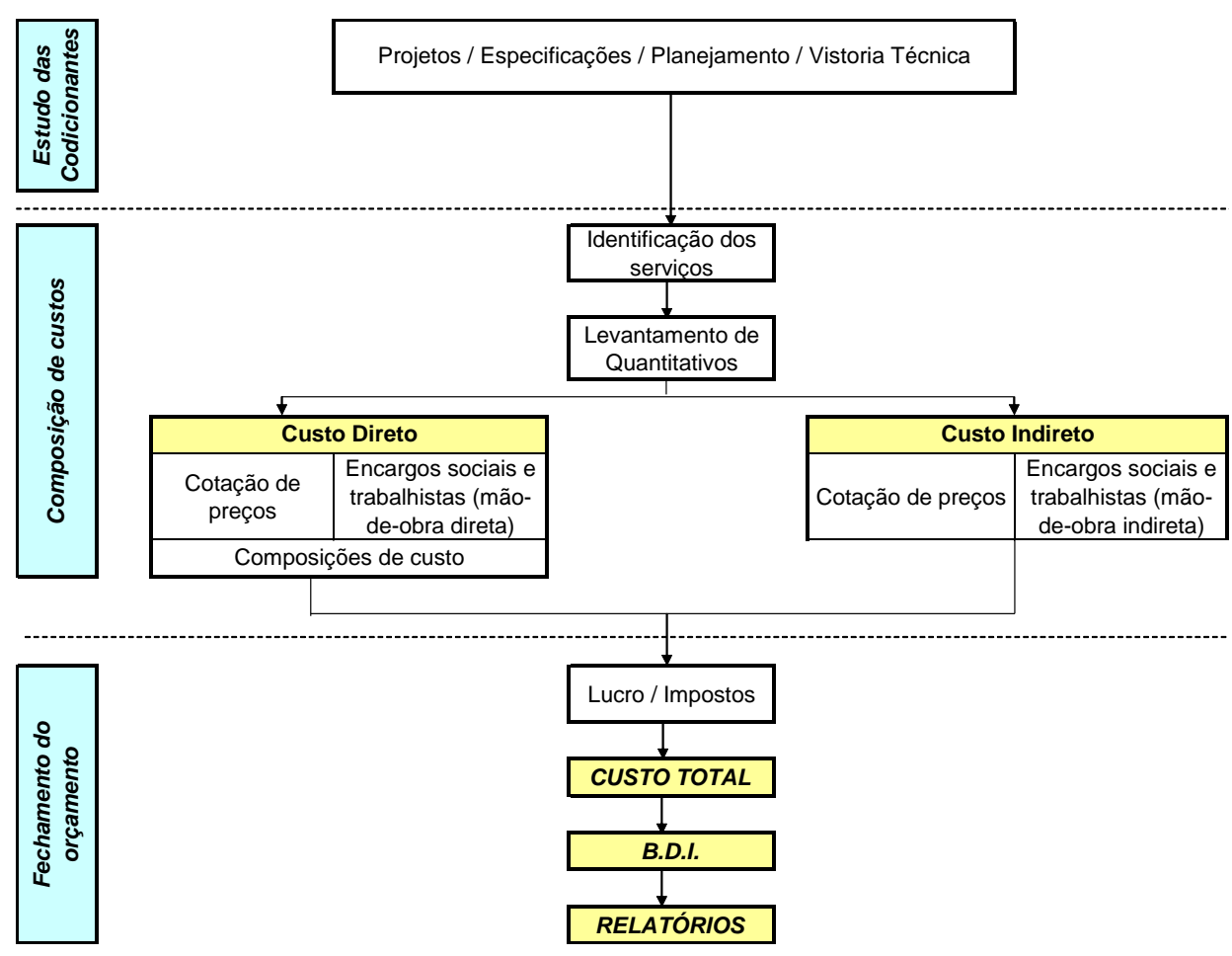

Figura 2 - Fluxograma das etapas para a elaboração de orçamentos Fonte: Marques de Jesus (2008). 
Além desse, outros métodos vêm sendo propostos, buscando-se aproximar cada vez mais o orçamento à realidade da produção. Um deles é o denominado orçamento operacional, que consiste no processo de compilar o custo total do trabalho considerando as operações constituintes ou atividades definidas na programação e a demanda acumulada de recursos comuns (CABRAL, 1988).

Segundo Kern e Formoso (2006), quando se elabora um orçamento operacional, a informação é mais detalhada, pois, em vez de orçar apenas os itens relativos às atividades de transformação da obra associados ao produto final (metros quadrados de parede, por exemplo), são orçadas todas as atividades envolvidas em sua produção, incluindo as que não agregam valor (por exemplo, o transporte dos componentes). Segundo a autora, o método auxilia na gestão da produção, mas destaca que seu uso exige mudanças profundas na estrutura de custos, bem como mais tempo dedicado a sua elaboração.

O trabalho de Kern e Formoso (2006) mostra claramente o potencial do método como ferramenta para o orçamento de obras de reabilitação; no entanto, não prescinde dos parâmetros de consumo e produtividade. Pelo contrário, tais parâmetros necessitam ser sempre atualizados segundo o sistema produtivo da empresa. Portanto, o problema para as obras de reabilitação permanece: os parâmetros devem ser determinados.

Em países europeus, onde essa atividade está avançada, a realização do orçamento tem sido facilitada pelo desenvolvimento de metodologias de análise de viabilidade da reabilitação de edifícios. Há, por exemplo, o TOBUS - Tool for Selecting Office Building Upgrading Solutions -, um método de diagnóstico para avaliação da viabilidade de reabilitação de edifícios de escritórios desenvolvido em conjunto pela Alemanha, França, Grécia, Suíça e Holanda, e amplamente utilizado por países europeus (FLOURENTZO; GENRE; ROULET, 2002). Também há um software especificamente voltado a edifícios habitacionais, amplamente difundido nos fins da década de 1990, o EPIQR - Energy Performance Indoor Environmental Quality Retrofit -, com foco nos custos e no desempenho energético de cada cenário previamente definido para a reabilitação do edifício em questão (FLOURENTZO; GENRE; ROULET, 2002). Nessa base de dados estão sendo registrados resultados de obras de reabilitação de edifícios realizadas em diferentes países e, a partir da compilação de suas características, tem sido possível estabelecer parâmetros médios que permitem diagnósticos mais precisos quanto ao comportamento esperado para edifícios reabilitados (CACCAVELI; GENRE, 2000). Além disso, tem-se possibilitado realizar estimativas de custos, permitindo a análise de viabilidade das reabilitações (JAGGS; PALMER, 2000).

Uma base de dados como esta, associada ao método de orçamento operacional, proposto por Kern e Formoso (2006), poderá, futuramente, ser utilizada para a análise de viabilidade de obras de reabilitação no Brasil. Observa-se, porém, que hoje tais metodologias não são facilmente aplicadas à situação brasileira porque não se dispõe de parâmetros adequados para a alimentação do sistema. Por isso, para os objetivos do presente trabalho, o método tradicional de elaboração de orçamento, aplicado às obras realizadas, mostra-se viável, sendo o utilizado.

\section{Método de pesquisa}

O trabalho foi desenvolvido durante os anos 2006 e 2007. Envolveu cinco empreendimentos de reabilitação, na cidade de São Paulo, para os quais foram realizados: levantamento da documentação técnica; visitas aos empreendimentos; e entrevistas não estruturadas com profissionais das empresas construtoras que participaram da produção dos empreendimentos estudados, buscando-se identificar os fatores que mais influenciam nos custos de produção e quais os métodos adotados para a estimativa de custos.

De posse da documentação técnica, o orçamento foi realizado segundo o fluxo de atividades da Figura 3, baseado no método tradicional de estimativas de custos. Os projetos de reabilitação e seus memoriais descritivos foram cuidadosamente estudados. Isso, somado às visitas realizadas, possibilitou detalhar as características principais dos empreendimentos - localização, utilização original e tecnologias construtivas empregadas na reabilitação. Realizou-se, em seguida, o levantamento dos serviços executados em cada uma das obras, apurando-se seus respectivos quantitativos, em que se considerou material, mão de obra e equipamentos envolvidos em cada unidade de serviço (FORMOSO et al., 1986). Esta última atividade também foi apoiada pelas visitas técnicas aos empreendimentos em obra.

A partir dos quantitativos, foram definidos seus respectivos custos diretos, empregando-se o Sistema de Preços, Custos e Índices (SIPCI), tendo-se como referência a data-base de novembro de 2006 (CAIXA..., 2006).

Para o cálculo dos custos indiretos, considerou-se a estrutura de cada obra e da respectiva empresa construtora. De acordo com Dias (2001), o Custo 
Indireto Total é obtido a partir da somatória dos custos de:

(a) mobilização e desmobilização dos equipamentos, de ferramentas e utensílios e de pessoal;

(b) administração local e central; riscos e eventuais; $\mathrm{e}$

(c) finalmente, encargos financeiros.

Uma vez determinados os custos diretos e indiretos, e considerando-se os impostos incidentes e o lucro da empresa, foi possível determinar o custo total do empreendimento (Equação 1):

$\mathrm{CT}=(\mathrm{CD}+\mathrm{CI}) /(1-\mathrm{I} \%-\mathrm{L} \%)$

Eq. 1

Onde:

CT: Custo total do empreendimento;

CD: Custos diretos;

CI: Custos indiretos;

i\%: Impostos sobre faturamento; e

L\%: Lucro.

A partir disso, obteve-se o valor correspondente ao BDI, ou seja, Bonificações e Despesas Indiretas (Equação 2):
BDI $(\%)=(\mathrm{CT} / \mathrm{CD})-1$

Eq. 2

Então, foram gerados os relatórios relativos aos orçamentos sintético e analítico e curva ABC, disponíveis em Marques de Jesus (2008). Analisaram-se, em seguida, os resultados, buscando-se definir parâmetros para subsidiar a elaboração de estimativas de custos para futuras obras.

\section{Caracterização dos empreendimentos analisados}

Constituem-se empreendimentos de reabilitação para habitação, sem envolvimento de restauro de patrimônio histórico, os que fizeram parte do Programa de Arrendamento Habitacional (PAR) com recursos oriundos do Fundo de Garantia por Tempo de Serviço (FGTS), destinado ao atendimento de famílias com renda mensal de 3 a 6 salários mínimos. Suas características estão apresentadas no Quadro 1.

Os projetos de reabilitação foram elaborados por assessorias técnicas ligadas a movimentos sociais, enquanto as construtoras foram selecionadas pela Caixa Econômica Federal, segundo critérios do programa PAR.

\begin{tabular}{|c|c|c|c|c|c|}
\hline & \multicolumn{5}{|c|}{ Empreendimentos de Reabilitação } \\
\hline & $\begin{array}{l}\text { Riskalla } \\
\text { Jorge }\end{array}$ & Maria Paula & Labor & $\begin{array}{c}\text { Hotel São } \\
\text { Paulo }\end{array}$ & $\begin{array}{c}\text { Joaquim } \\
\text { Carlos }\end{array}$ \\
\hline & & 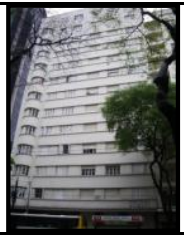 & 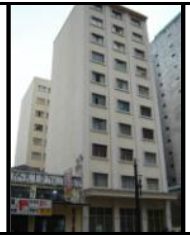 & 10 & 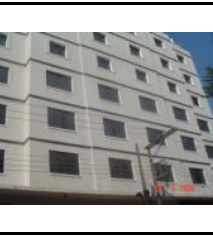 \\
\hline Localização (São Paulo - SP) & $\begin{array}{c}\text { Rua } \\
\text { Riskallah } \\
\text { Jorge, } 50\end{array}$ & $\begin{array}{l}\text { Rua Maria } \\
\text { Paula, } 171\end{array}$ & $\begin{array}{c}\text { Rua } \\
\text { Brigadeiro } \\
\text { Tobias, } 298\end{array}$ & $\begin{array}{c}\text { Rua São } \\
\text { Francisco, } \\
\text { esquina com } \\
\text { a Av. } 23 \text { de } \\
\text { Maio }\end{array}$ & $\begin{array}{c}\text { Rua Joaquim } \\
\text { Carlos, } 76 . \\
\text { Pari }\end{array}$ \\
\hline Uso original & $\begin{array}{c}\text { Comercial } \\
\text { (Escritórios) }\end{array}$ & Residencial & $\begin{array}{c}\text { Comercial } \\
\text { (Escritórios) }\end{array}$ & $\begin{array}{c}\text { Comercial } \\
(\text { Hotel })\end{array}$ & Residencial \\
\hline Ano de construção do edifício & 1947 & 1941 & 1946 & 1946 & 1965 \\
\hline Pavimentos (Total) & 19 & 14 & 11 & 21 & 9 \\
\hline Ano da reabilitação do edifício & fev/2002 & $\mathrm{dez} / 2003$ & $\mathrm{jan} / 2004$ & set/2006 & set/2006 \\
\hline Unidades habitacionais & 167 & 75 & 84 & 152 & 93 \\
\hline Área $\left(\mathrm{m}^{2}\right)$ & $7.472,90$ & $3.909,14$ & $4.522,93$ & $8.102,14$ & $5.379,60$ \\
\hline Exigências para reabilitação & $\begin{array}{c}\text { Fachada } \\
\text { tombada, a ser } \\
\text { preservada }\end{array}$ & Não houve & Não houve & $\begin{array}{c}\text { Fachada } \\
\text { tombada, a ser } \\
\text { preservada }\end{array}$ & Não houve \\
\hline
\end{tabular}

Quadro 1 - Caracterização dos empreendimentos objeto do estudo 
O orçamento elaborado para cada edifício está totalmente vinculado a suas condições prévias, ao projeto de reabilitação e às tecnologias construtivas empregadas (Quadro 2).

\section{Apresentação e análise dos resultados}

A partir dos orçamentos e relatórios elaborados (MARQUES DE JESUS, 2008), apresentam-se no
Quadro 3 os parâmetros de custo para seus subsistemas.

O custo por unidade habitacional e o custo por área construída (Quadro 3) referem-se aos custos diretos; os custos indiretos não estão considerados. Da análise desses resultados depreendem-se os pontos a seguir.

\begin{tabular}{|c|c|c|c|c|c|c|}
\hline & & \multicolumn{5}{|c|}{ Empreendimentos Reabilitados para Habitação de Interesse Social } \\
\hline & & Riskalla Jorge & Maria Paula & Labor & Hotel São Paulo & Joaquim Carlos \\
\hline $\begin{array}{l}\text { Subsis } \\
\text {-tema }\end{array}$ & Serviço & \multicolumn{5}{|c|}{ Tecnologia empregada } \\
\hline 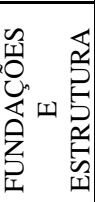 & 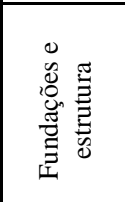 & $\begin{array}{l}\text { Sem necessidade de } \\
\text { recuperação } \\
\text { estrutural. }\end{array}$ & $\begin{array}{l}\text { Sem necessidade de } \\
\text { recuperação } \\
\text { estrutural. Nova } \\
\text { estrutura metálica } \\
\text { para ampliação da } \\
\text { área de circulação. }\end{array}$ & \begin{tabular}{|l|} 
Necessidade de \\
recuperação da \\
fundação e estrutura \\
em C.A.; execução \\
de pavimento em \\
alvenaria estrutural.
\end{tabular} & $\begin{array}{l}\text { Necessária construção } \\
\text { de estrutura em } \\
\text { alvenaria estrutural para } \\
\text { nova escada de } \\
\text { emergência. }\end{array}$ & $\begin{array}{l}\text { Sem necessidade de } \\
\text { recuperação } \\
\text { estrutural. }\end{array}$ \\
\hline \multirow{2}{*}{ 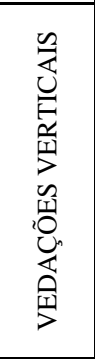 } & $\frac{8}{8}$ & $\begin{array}{l}\text { Novas divisórias } \\
\text { com bloco de } \\
\text { concreto celular. }\end{array}$ & $\begin{array}{l}\text { Novas divisórias } \\
\text { com bloco cerâmico. }\end{array}$ & $\begin{array}{l}\text { Novas divisórias com } \\
\text { bloco cerâmico. }\end{array}$ & $\begin{array}{l}\text { Novas divisórias com } \\
\text { bloco cerâmico. }\end{array}$ & $\begin{array}{l}\text { Novas divisórias } \\
\text { com bloco cerâmico. }\end{array}$ \\
\hline & 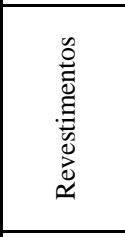 & $\begin{array}{l}\text { Argamassa de } \\
\text { cimento e areia } \\
\text { (chapisco e } \\
\text { emboço); } \\
\text { revestimento } \\
\text { cerâmico nas áreas } \\
\text { molhadas. } \\
\end{array}$ & $\begin{array}{l}\text { Argamassa de } \\
\text { cimento e areia } \\
\text { (chapisco e emboço); } \\
\text { revestimento } \\
\text { cerâmico nas áreas } \\
\text { molhadas. }\end{array}$ & $\begin{array}{l}\text { Argamassa de } \\
\text { cimento e areia } \\
\text { (chapisco e emboço); } \\
\text { revestimento } \\
\text { cerâmico nas áreas } \\
\text { molhadas. }\end{array}$ & $\begin{array}{l}\text { Aplicação de gesso liso } \\
\text { nas áreas secas das } \\
\text { unidades habitacionais; } \\
\text { revestimento cerâmico } \\
\text { nas áreas molhadas; } \\
\text { argamassa de cimento e } \\
\text { areia nas áreas comuns. }\end{array}$ & $\begin{array}{l}\text { Argamassa de } \\
\text { cimento e areia } \\
\text { (chapisco e emboço); } \\
\text { revestimento } \\
\text { cerâmico nas áreas } \\
\text { molhadas. }\end{array}$ \\
\hline \multirow{5}{*}{ 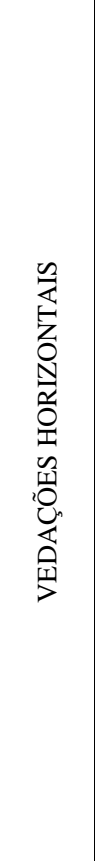 } & 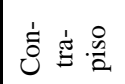 & $\begin{array}{l}\text { Aproveitado o } \\
\text { existente. }\end{array}$ & $\begin{array}{l}\text { Novo contrapiso em } \\
\text { argamassa. }\end{array}$ & $\begin{array}{l}\text { Aproveitado o } \\
\text { existente. }\end{array}$ & $\begin{array}{l}\text { Novo contrapiso em } \\
\text { argamassa. }\end{array}$ & $\begin{array}{l}\text { Aproveitado o } \\
\text { existente. }\end{array}$ \\
\hline & 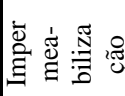 & $\begin{array}{l}\text { Membrana asfáltica } \\
\text { nas áreas molhadas. }\end{array}$ & $\begin{array}{l}\text { Membrana asfáltica } \\
\text { nas áreas molhadas. }\end{array}$ & $\begin{array}{l}\text { Membrana asfáltica } \\
\text { nas áreas molhadas. }\end{array}$ & $\begin{array}{l}\text { Membrana asfáltica nas } \\
\text { áreas molhadas. }\end{array}$ & $\begin{array}{l}\text { Membrana asfáltica } \\
\text { nas áreas molhadas. }\end{array}$ \\
\hline & 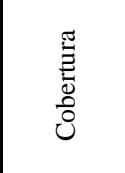 & $\begin{array}{l}\text { Substituição do } \\
\text { telhado, calhas de } \\
\text { drenagem e } \\
\text { impermeab. do } \\
\text { terraço. }\end{array}$ & $\begin{array}{l}\text { Substituição do } \\
\text { telhado e calhas de } \\
\text { drenagem. }\end{array}$ & $\begin{array}{l}\text { Substituição do } \\
\text { telhado e calhas de } \\
\text { drenagem. }\end{array}$ & $\begin{array}{l}\text { Substituição das calhas } \\
\text { de drenagem e } \\
\text { impermeab. do terraço. }\end{array}$ & $\begin{array}{l}\text { Substituição do } \\
\text { telhado, calhas de } \\
\text { drenagem e } \\
\text { impermeab. do } \\
\text { terraço. }\end{array}$ \\
\hline & 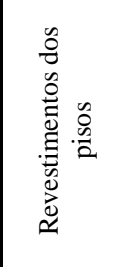 & $\begin{array}{l}\text { Recuperação do } \\
\text { piso existente em } \\
\text { taco de madeira } \\
\text { (unidades } \\
\text { habitacionais) e } \\
\text { cerâmico } \\
\text { (circulação). }\end{array}$ & $\begin{array}{l}\text { Sem revestimento } \\
\text { nas áreas secas, e } \\
\text { revestimento } \\
\text { cerâmico nas áreas } \\
\text { molhadas. }\end{array}$ & $\begin{array}{l}\text { Recuperação do piso } \\
\text { existente em taco de } \\
\text { madeira (unidades } \\
\text { habitacionais) e } \\
\text { ardósia (circulação). }\end{array}$ & $\begin{array}{l}\text { Novo revestimento } \\
\text { cerâmico nas áreas } \\
\text { molhadas; recuperação } \\
\text { do revestimento } \\
\text { cerâmico existente nas } \\
\text { áreas comuns. }\end{array}$ & $\begin{array}{l}\text { Novo revestimento } \\
\text { cerâmico nas } \\
\text { unidades } \\
\text { habitacionais; } \\
\text { aproveitamento do } \\
\text { revestimento } \\
\text { cerâmico existente } \\
\text { nas áreas comuns. }\end{array}$ \\
\hline & 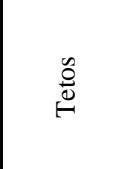 & $\begin{array}{l}\text { Revisão do reboco } \\
\text { existente e pintura } \\
\text { completa; forro de } \\
\text { gesso nos } \\
\text { banheiros. }\end{array}$ & $\begin{array}{l}\text { Revisão do reboco } \\
\text { existente e pintura } \\
\text { completa; forro de } \\
\text { gesso nos banheiros. }\end{array}$ & $\begin{array}{l}\text { Revisão do reboco } \\
\text { existente e pintura } \\
\text { completa; forro de } \\
\text { gesso nos banheiros. }\end{array}$ & $\begin{array}{l}\text { Revisão do reboco } \\
\text { existente e pintura } \\
\text { completa; forro de } \\
\text { gesso nos banheiros e } \\
\text { áreas comuns. }\end{array}$ & $\begin{array}{l}\text { Revisão do reboco } \\
\text { existente e pintura } \\
\text { completa; forro de } \\
\text { gesso nos banheiros } \\
\text { e áreas comuns. }\end{array}$ \\
\hline
\end{tabular}

Quadro 2 - Estudos de caso: tecnologias construtivas empregadas 
Ambiente Construído, Porto Alegre, v. 11, n. 2, p. 57-72, abr./jun. 2011.

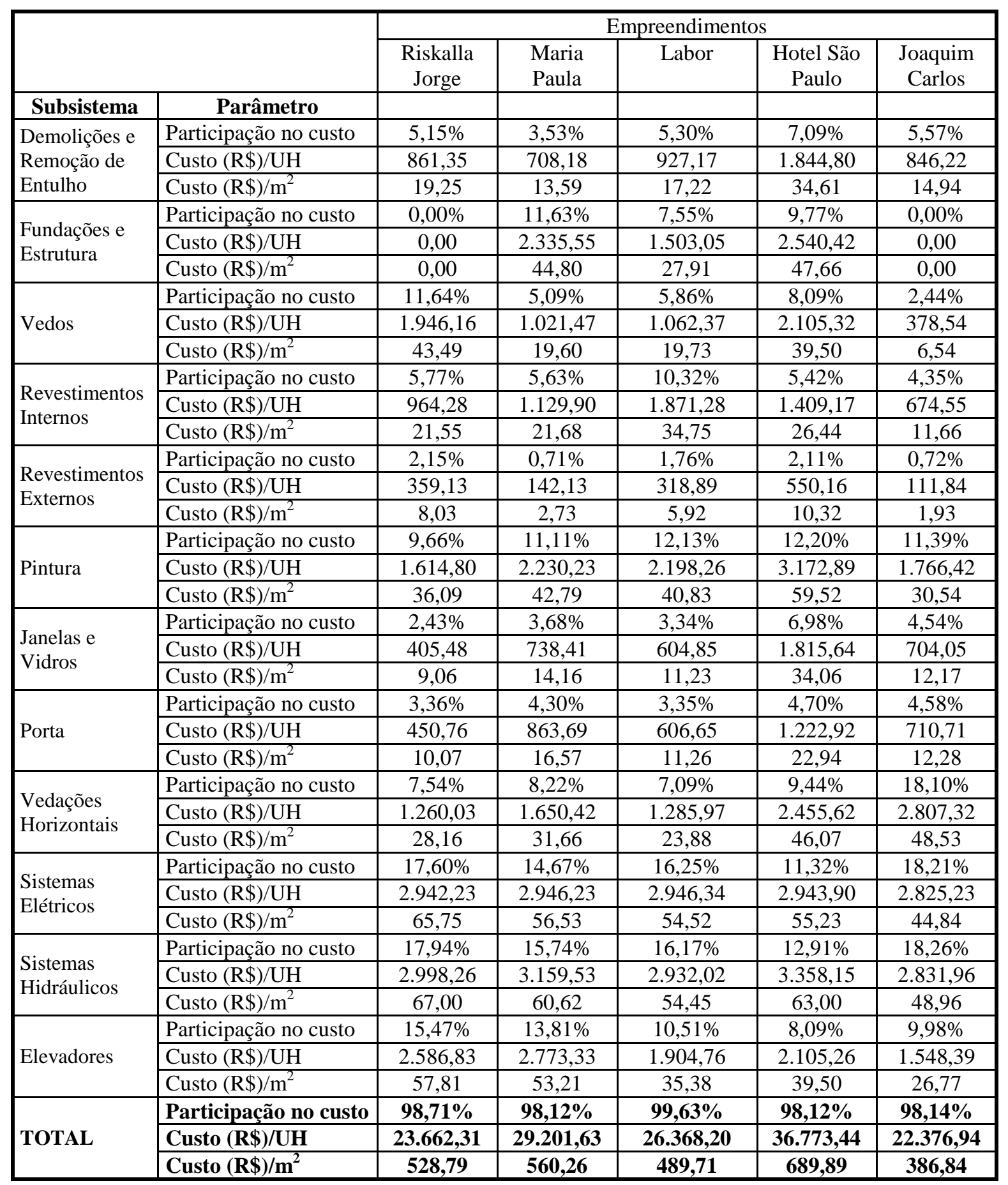

Quadro 3 - Síntese de parâmetros de custos para obras de reabilitação por subsistema e serviços do edifício (data-base: novembro/2006)

\section{Demolições e remoção de entulho}

O Hotel São Paulo foi a obra que apresentou o maior custo percentual de serviço de demolição por unidade habitacional e área construída, particularmente porque foi necessária a retirada de grande volume de material referente à remoção da escada metálica de emergência existente no vão central, e de caixas d'água em pavimentos intermediários. Em todos os casos, o custo dessa atividade é mais expressivo do que nos casos de obras novas, que sequer chega a $1 \%$.

\section{Fundações e estrutura}

A participação desse subsistema no custo total da obra variou de um empreendimento para outro conforme a necessidade de reforço (Labor) ou 
ampliação da área (Hotel São Paulo e Maria Paula). Há autores que afirmam que a viabilidade do empreendimento de reabilitação está condicionada ao nível de intervenção na estrutura e na fundação; no entanto, pelos dados dos empreendimentos estudados, observa-se que isso é relativo, sobretudo quando a intervenção possibilita a ampliação da área construída. Nos casos em que houve intervenção na estrutura, seu custo relativo é expressivo (7-12\%).

\section{Vedos e revestimentos internos}

Nas situações em que houve o completo aproveitamento das paredes existentes (Joaquim Carlos), o custo relativo diminuiu. Naqueles com maior compartimentação dos ambientes originais (Maria Paula e Hotel São Paulo), sua participação nos custos foi maior. De forma geral, os custos relativos foram influenciados por: especificação do material empregado; mudança de uso do edifício; grau de intervenção (alterações, modificações); e estado de conservação das paredes. Considerando todos os casos, sua variação esteve entre $7 \%$ e $17 \%$.

\section{Revestimentos externos}

$\mathrm{O}$ que de fato influenciou nos custos relativos desse serviço foi o estado de conservação da fachada e, consequentemente, o grau de intervenção para sua recuperação. As fachadas protegidas pelo Patrimônio Histórico consumiram mais recursos $(\sim 2 \%)$. Porém, em todos os casos, não se tratou de custo expressivo (1-2\%) porque não houve sua substituição completa. Trata-se, pois, de um serviço que pode resultar em custos percentuais maiores em função das condições de conservação.

\section{Pintura}

Teve participação significativa no custo global para todos os empreendimentos (10\% a 12\%). Assim, para o orçamento podem ser empregados parâmetros próximos aos de uma obra nova, porque usualmente todo o edifício é pintado novamente, tanto interna como externamente.

\section{Janelas e vidros}

No Hotel São Paulo o custo por unidade habitacional e por área construída foi próximo de 2,5 vezes ao dos demais empreendimentos. Isso se deveu, em parte, à necessidade de substituição de todas as janelas do edifício com medidas específicas dos vãos, uma vez que se tratava de fachada tombada. Nas demais obras, a maioria foi simplesmente recuperada. Nos contextos analisados, o custo de janelas novas foi maior do que o de recuperação. Porém, isso pode variar para cada caso, inclusive em função da disponibilidade de mão de obra. Por isso, é difícil estabelecer uma regra. É possível assumir que, para situações comuns, a troca das janelas pode significar duas a três vezes mais investimento do que sua recuperação. Quanto às portas, nos casos dos edifícios Riskalla Jorge e Labor, onde houve recuperação parcial das portas existentes, o custo por unidade habitacional foi menor quando comparado às demais, onde houve substituição completa. Também nesse caso as condições de funcionamento e durabilidade são fundamentais na tomada de decisão, seja pela substituição ou aproveitamento, sobretudo considerando-se a diferença reduzida entre os extremos $(1,5 \%)$.

\section{Vedações horizontais}

Deve-se dar destaque à obra Joaquim Carlos, onde houve a substituição completa do revestimento cerâmico em todas as unidades habitacionais, além de grande recuperação exigida para o forro, o que não ocorreu nas demais. Fundamentalmente por esse motivo, essa obra apresentou o maior custo por área construída. Em todos os casos, porém, o revestimento de piso e teto teve custo relativo importante, podendo-se estimar, em média, algo em torno de $8 \%$.

\section{Sistemas elétricos}

Em todos os casos os sistemas elétricos foram completamente substituídos, o que justifica a semelhança na participação desses serviços nos custos diretos, que variou entre $15 \%$ e $18 \%$, exceto para uma das obras. Destaca-se, ainda, que o custo dos sistemas elétricos por unidade habitacional foi praticamente o mesmo em todas as obras, uma vez que os projetos das unidades eram muito semelhantes entre si, pois previam instalações mínimas necessárias.

\section{Sistemas hidráulicos}

A participação desses serviços nos custos diretos variou de $16 \%$ a $18 \%$, exceto para um dos casos. Também nesse subsistema o custo por unidade habitacional resultou semelhante para todos os empreendimentos.

\section{Elevadores}

Para o cálculo dos custos dos elevadores, foram consideradas cabines com as mesmas dimensões em todos os edifícios. Além disso, foram adotadas cabines de utilização residencial para 6 pessoas. Os fatores que influenciaram no custo de produção 
foram o número de elevadores que atendem o edifício e o número de pavimentos. $\mathrm{O}$ custo dos elevadores é significativo no custo total da obra (8$16 \%)$.

O Quadro 3 permite concluir, ainda, que os serviços relativos aos sistemas de vedações verticais (vedo, revestimento e pintura) somados aos prediais representam mais de $50 \%$ dos custos da obra de reabilitação. Portanto, é importante que se pense em soluções de projeto que permitam maior grau de racionalização para eles.

A elaboração do orçamento permitiu, ainda, determinar alguns indicadores de custos dos empreendimentos (Quadro 4).

Do Quadro 4 conclui-se que o Hotel São Paulo apresentou custo relativo à área construída maior que o das demais obras, possivelmente em função de fatores como adaptação do uso original do edifício (de hotel para habitação), exigência de nova escada de segurança e de preservação das características originais da fachada. Por outro lado, o edifício Joaquim Carlos apresentou o menor custo. Nele foi mantido o uso original e não houve necessidade de intervenção nas fundações e estrutura. Além disso, houve extenso aproveitamento de vedos e revestimentos internos e externos. O grau de intervenção relacionado à extensão e complexidade das modificações previstas é, pois, um dos aspectos que condicionam o custo total de produção dessas obras.

Outro indicador importante refere-se ao custo de mão de obra, que colabora com cerca de $50 \%$ do custo total. É evidente que a redução dos custos de produção deve passar, necessariamente, pelo aumento da produtividade e pela eliminação da mão de obra não qualificada ( $\sim 25 \%$ do custo total), usualmente alocada em atividades não produtivas.

$\mathrm{O}$ orçamento realizado permite ainda comparar os indicadores macro das obras de reabilitação com valores de referência para obras novas, supondo-se que fossem construídas com as mesmas condições de área dos edifícios reabilitados (Quadro 5). Foram considerados custos diretos de produção de obra nova, adotando-se custo por área construída de $\mathrm{R} \$ 553,58 / \mathrm{m}^{2}$, a partir do projeto habitacional PR12-4QP4050 (CAIXA..., 2006), utilizando-se mesma data-base dos orçamentos realizados.

\begin{tabular}{|c|c|c|c|c|c|}
\hline & \multicolumn{5}{|c|}{ Empreendimentos } \\
\hline & $\begin{array}{l}\text { Riskalla } \\
\text { Jorge }\end{array}$ & Maria Paula & Labor & $\begin{array}{l}\text { Hotel São } \\
\text { Paulo }\end{array}$ & $\begin{array}{l}\text { Joaquim } \\
\text { Carlos }\end{array}$ \\
\hline Uso Original & $\begin{array}{c}\text { Comercial } \\
\text { (Escritórios) }\end{array}$ & Residencial & $\begin{array}{l}\text { Comercial } \\
\text { (Escritórios) }\end{array}$ & $\begin{array}{l}\text { Comercial } \\
\text { (Hotel) }\end{array}$ & Residencial \\
\hline \multicolumn{6}{|l|}{ Dados Físicos } \\
\hline $\mathrm{N}^{\circ}$ Pavimentos & 19 & 14 & 11 & 21 & 9 \\
\hline Unidades Habitacionais & 167 & 75 & 84 & 152 & 93 \\
\hline Área $\left(\mathrm{m}^{2}\right)$ & $7.472,90$ & $3.909,14$ & $4.522,93$ & $8.102,14$ & $5.379,60$ \\
\hline \multicolumn{6}{|l|}{ Custos } \\
\hline Custo Direto (R\$) & $2.791 .691,03$ & $1.505 .900,75$ & $1.522 .816,23$ & $3.954 .273,53$ & $1.442 .706,20$ \\
\hline Custo Total R\$) & $3.951 .606,45$ & $2.190 .122,43$ & $2.214 .928,49$ & $5.589 .563,05$ & $2.081 .055,37$ \\
\hline BDI $(\%)$ & $42 \%$ & $46 \%$ & $46 \%$ & $42 \%$ & $45 \%$ \\
\hline \multicolumn{6}{|l|}{ Indicadores } \\
\hline $\begin{array}{c}\text { Custo Total (R\$) / Unidade } \\
\text { Hab. }\end{array}$ & $23.662,31$ & $29.201,63$ & $26.368,20$ & $36.773,44$ & $22.376,94$ \\
\hline Custo Total $(\mathrm{R} \$) / \mathrm{m}^{2}$ & 528,79 & 560,26 & 489,71 & 689,89 & 386,84 \\
\hline $\begin{array}{c}\text { Custo Mão de Obra / Custo } \\
\text { Total }\end{array}$ & $46,81 \%$ & $53,33 \%$ & $47,96 \%$ & $52,45 \%$ & $46,86 \%$ \\
\hline $\begin{array}{l}\text { Custo de Mão de Obra Não } \\
\text { Qualificada / Custo Total }\end{array}$ & $22,84 \%$ & $28,56 \%$ & $19,76 \%$ & $27,48 \%$ & $22,89 \%$ \\
\hline $\begin{array}{c}\text { Custo de Mão de Obra } \\
\text { Qualificada / Custo Total }\end{array}$ & $23,97 \%$ & $24,77 \%$ & $28,20 \%$ & $24,97 \%$ & $23,97 \%$ \\
\hline Custo Material / Custo Total & $53,19 \%$ & $46,67 \%$ & $52,04 \%$ & $47,55 \%$ & $53,14 \%$ \\
\hline
\end{tabular}

Quadro 4 - Síntese de dados e indicadores de custos para as obras de reabilitação estudadas (data-base: novembro/2006 
Em todos os casos, constata-se que o custo da reabilitação é menor que o estimado para obra nova. Em um dos casos é praticamente a metade, ainda que a vantagem tenha sido reduzida para o Hotel São Paulo, possivelmente devido a sua complexidade. Em média, tem-se uma redução de um terço em relação ao custo de obra nova, lembrando-se que para esta seria necessário adicionar, ainda, o custo de demolição do edifício antigo; além disso, o potencial construtivo do terreno resultante seria muito menor devido à legislação de uso e ocupação do solo; assim, a diferença seria ainda maior. Portanto, mesmo considerando-se apenas os custos de produção, a obra de reabilitação tende a ser mais econômica.

Tomando-se esse cenário como referência, conclui-se que a reabilitação de edifícios deverá crescer nos próximos anos e, por isso, a atividade de orçamento ganhará cada vez mais importância. Assim, na sequência, apresentam-se algumas recomendações para sua elaboração.

\section{Recomendações para a elaboração de orçamentos de obras de reabilitação}

A partir dos parâmetros de custos sintetizados nos Quadro 3, 4 e 5 e das análises anteriores, é possível concluir que:

(a) a mudança de uso tem impacto expressivo nos serviços de demolição e retirada de entulho; nas obras Maria Paula e Joaquim Carlos, sem mudança do uso original, esses serviços apresentaram custos reduzidos. Assim, recomenda-se fazer um levantamento de quantitativos minucioso de todos os elementos do edifício que serão retirados, para avaliar o seu impacto no custo total. Para situações comuns pode-se adotar um índice médio de $5 \%$ do custo total, podendo-se ter uma diminuição de $2 \%$ para situações em que as alterações em vedo e estrutura forem reduzidas em relação a sua quantidade total, e um aumento de $2 \%$ quando tais alterações forem mais expressivas;

(b) a necessidade de recuperação das fundações e da estrutura do edifício pode trazer grandes impactos sobre os custos. Nas obras Maria Paula, Labor e Hotel São Paulo significou aproximadamente $10 \%$ do custo direto da obra, além de implicar custos mais elevados de produção. Portanto, é necessária a análise detalhada das condições estruturais do edifício sob as novas condições arquitetônicas, para mensuração precisa dos custos envolvidos. Considerando-se as informações disponíveis do Quadro 3, poder-se-ia adotar em obras sem necessidade de recuperação estrutural a faixa percentual inferior $(0 \%)$ para esse subsistema, enquanto para obras cuja recuperação estrutural seja exigida utiliza-se até o percentual da faixa superior $(10 \%)$;

(c) os custos de produção dos vedos e revestimentos internos são determinados por fatores como mudança do uso do edifício, área das novas unidades habitacionais (quanto menor, maior a incidência de vedos e revestimentos por unidade de área), estado de conservação das paredes e revestimentos existentes, especificação dos materiais e componentes e forma de execução dos sistemas prediais. Os resultados obtidos para esse subsistema indicam que representa de $5 \%$ a $15 \%$ do custo total;

(d) o custo dos revestimentos externos é influenciado tanto pelo estado de conservação do revestimento como pela necessidade ou não de atividades de restauro. Assim, para as situações comuns, em que grande parte do revestimento externo é aproveitada, como os casos estudados, o custo relativo manteve-se ao redor de $2 \%$ do total. Para situações que exijam completa retirada do revestimento original e aplicação de novo, esse percentual poderá, inclusive, superar o patamar de obras novas, uma vez que exigirá a retirada do revestimento antigo;

(e) os custos de pintura são proporcionais à área de fachada e vedos internos do edifício, independentemente de seu estado de conservação, pois o edifício sempre receberá nova pintura, uma vez que, de forma geral, não se aproveita a pintura existente. Trata-se de um valor relativo expressivo, ao redor de $10 \%$;

\begin{tabular}{|l|c|c|c|c|c|}
\hline & \multicolumn{5}{|c|}{ Empreendimentos } \\
\cline { 2 - 6 } & Riskalla Jorge & Maria Paula & Labor & Hotel São Paulo & Joaquim Carlos \\
\hline $\begin{array}{l}\text { Custo de produção de } \\
\text { obra nova (R\$) }\end{array}$ & $4.136 .847,98$ & $2.164 .021,72$ & $2.503 .803,59$ & $4.485 .182,66$ & $2.978 .038,97$ \\
\hline $\begin{array}{l}\text { Custo de Reabilitação } \\
\text { (R\$) }\end{array}$ & $2.791 .691,03$ & $1.505 .900,75$ & $1.522 .816,23$ & $3.954 .273,53$ & $1.442 .706,20$ \\
\hline Diferença (\%) & $32,52 \%$ & $30,41 \%$ & $39,18 \%$ & $11,84 \%$ & $51,56 \%$ \\
\hline
\end{tabular}

Quadro 5 - Comparação entre custos diretos de produção de obras novas e de reabilitação (data-base: 2006) 
(f) recuperar janelas e portas reduz o custo desses serviços e também o de demolição e geração de entulho. Dos estudos realizados pode-se dizer que houve variação de $7 \%$ a $10 \%$, considerando-se o extremo inferior quando há grande parte de recuperação de portas e janelas, enquanto o superior prevê a maior parte de trocas. A tomada de decisão, porém, deve considerar as condições de funcionamento e durabilidade desses elementos após a manutenção, em função da vida útil esperada para o edifício. Segundo Costa (2009), notadamente as janelas são críticas, pois constatou que $30 \%$ a $60 \%$ do total de queixas de moradores de edifícios reabilitados referem-se a elas;

(g) os sistemas elétricos e hidráulicos dos edifícios apresentam participação expressiva nos custos de produção, pois, de modo geral, não há aproveitamento das antigas instalações em função da idade dos edifícios e de sua obsolescência funcional. Por se tratar de subsistemas de grande complexidade, no levantamento dos quantitativos deve-se considerar a interferência com outros subsistemas, que pode ser minimizada com o emprego de tecnologias construtivas mais racionalizadas. Representa de $25 \%$ a $35 \%$ do custo total;

(h) outro serviço importante diz respeito aos elevadores, pois, como afirma Costa (2009), em diversas obras onde foi realizada sua recuperação, a necessidade de manutenção é mais intensa, acarretando em aumento de custos de condomínio, além de gerar interferências nas instalações elétricas de áreas comuns do edifício. Sua participação esteve entre $8 \%$ e15\%; e

(i) ressalta-se, ainda, que os serviços referentes aos sistemas prediais e vedações verticais (vedos, revestimentos e pintura) implicam maior participação no custo do empreendimento $(50 \%$ ou mais). Sabendo-se que há grande interação entre ambos, uma recomendação é a utilização de tecnologias que possibilitem a redução de seus custos de produção.

Ainda que os dados levantados até aqui não permitam extrair índices precisos para a obra de reabilitação, foi possível identificar que eles se encontram dentro de certos limites (Quadro 6).

É preciso salientar que a utilização de tais parâmetros em estimativas de custo deve ser feita para obras de reabilitação para habitação de interesse social. Caso a finalidade seja distinta, como para habitação de alto padrão ou para fins comerciais, outros parâmetros deverão ser empregados.

\section{Considerações finais}

A realização do trabalho demonstrou que estimar custos de produção de obras de reabilitação é uma tarefa complexa, que deve levar em conta aspectos como legislação, logística de obra e características originais dos edifícios, entre muitos outros que influenciam diretamente no custo total, o que fica claramente demonstrado pelos valores apurados de BDI $(\sim 45 \%)$.

Ainda que não conclusivos e limitados pelo número de empreendimentos analisados, os resultados alcançados neste trabalho podem servir de referencial, tanto para elaboração de orçamentos, como para auxiliar projetistas a avaliar os impactos que as decisões tomadas no projeto poderão implicar sobre os custos finais dos empreendimentos.

Como bem afirmam Ali, Rahmat e Hassan (2008), as decisões de projeto têm implicações importantes para o custo, qualidade, duração e recursos alocados para o empreendimento de reabilitação. Destacam ainda que, para uma adequada tomada de decisão, a informação é fundamental.

Por isso, urge o desenvolvimento de novas abordagens para a elaboração do orçamento e para a gestão de custos de obras de reabilitação. Os métodos tradicionais têm suas limitações, uma vez que, muitas vezes, não é possível considerarem-se as especificidades das obras de reabilitação. A associação de novos softwares aos conceitos do orçamento operacional, como proposto por Kern (2006), é um caminho a ser trilhado em trabalhos futuros.

\begin{tabular}{|l|c|}
\hline \multicolumn{1}{|c|}{ Subsistema } & Participação no custo (\%) \\
\hline Demolições e remoção de entulho & $3-7$ \\
\hline Fundações e estrutura & $0-10$ \\
\hline Vedos, revestimentos verticais e pintura & $14-35$ \\
\hline Esquadrias & $7-10$ \\
\hline Revestimento de piso e teto & $7-10$ \\
\hline Sistemas elétricos e hidráulicos & $25-35$ \\
\hline Elevadores & $8-15$ \\
\hline
\end{tabular}

Quadro 6 - Intervalo de participação percentual do custo de produção de cada subsistema do edifício no custo total de obras de reabilitação 


\section{Referências}

AGUIAR, J.; CABRITA, A. M. R.; APPLETON. J. Guião de Apoio à Reabilitação de Edifícios Habitacionais. 6. ed. Lisboa: Laboratório Nacional de Engenharia Civil, 2002. 2 v.

ALI, A. S.; RAHMAT, I.; HASSAN, H. Involvement of Key Design Participants in Refurbishment Design Process. Facilities, v. 26, v. 9/10, p. 389-400, 2008.

ANJANEYULU, L. Building Rehabilitation: a promissing tool for urban revitalization in Detroit. Michigan. 2003. 351 p. Thesys (Construction Management Program) - Michigan State University, Detroit, 2003.

ASMUSSEN, M. W. Entendendo o Jargão Hoteleiro: conceitos e terminologia básicos do ramo hoteleiro. Real Estate: Economia \& Mercados. v. 1, n. 1, p. 1-41, jan. 2004.

ASSUMPÇÃO, J. F. P.; FUGAZZA, A. E. C. Execução de Orçamento por Módulos para Obras de Construção de Edifícios. In: ENCONTRO NACIONAL DE TECNOLOGIA DO AMBIENTE CONSTRUÍDO, 8., 2000, Salvador. Anais... Salvador, 2000. v. 1, p. 469-476.

BCSD PORTUGAL. Conselho Empresarial para o Desenvolvimento Sustentável. Reabilitação: a melhor via para construção. Lisboa, 2004. Disponível em: <http://www.bcsdportugal.org/>. Acesso em: 05 nov. 2011.

BOMFIM, V. C. Espaços Edificados Vazios na Área Central da Cidade de São Paulo e a Dinâmica Urbana. 2004. 2 v. Dissertação (Mestrado em Engenharia) - Escola Politécnica, Universidade de São Paulo, São Paulo, 2004.

BRANCATELLI, R. "Cirurgia Plástica" Chega a Dobrar Preços de Prédios. Jornal Estado de São Paulo, São Paulo, 27 julho 2010. Disponível em: <http://www.estadao.com.br/estadaodehoje/20100 727/not_imp586418,0.php>. Acesso em: 28 out. 2010.

CABRAL, E. C. C. Proposta de Metodologia de Orçamento Operacional para Obras de Edificação. 1988. Dissertação (Mestrado em Engenharia Civil) - Escola de Engenharia, Universidade de Santa Catarina, Florianópolis, 1988.

CACCAVELLI, D.; GENRE, J. L. Diagnosis of the Degradation State of Building and Cost Evaluation of Induced Retrofit Works. Energy and Buildings, v. 31, n. 2, p. 159-165, 2000.
CAIXA Econômica Federal. Programa de Revitalização de Sítios Históricos - Caixa: parceria na reabilitação urbana de áreas centrais. Disponível em:

<https://webp.caixa.gov.br/urbanizacao/Publicacao /Texto/sitios/prsh.htm>. Acesso em: 29 jun. 2011.

CAIXA Econômica Federal. SINAPI: Sistema Nacional de Pesquisa de Custos e Índices da Construção Civil. 2006. Disponível em: $<$ https://webp.caixa.gov.br/casa/sinapi/index.asp? menu=0>. Acesso em: 11 nov. 2006.

CAMBIAGHI, H. Será Preciso Educar a População ou Até Pagar Condomínio. Jornal Estado de São Paulo, São Paulo, 20 setembro 2010. Disponível em:

<http://www.estadao.com.br/estadaodehoje/20100 920/not_imp612338,0.php>. Acesso em: $14 \mathrm{dez}$. 2011.

CARVALHO, K. Construir ou Reformar? Construção e Mercado, São Paulo, v. 46, p. 4852, 2005.

CIANCIARDI, G.; MONTEIRO, R. Z.; BRUNA, G. C. Parâmetros de Sustentabilidade Ecológicos na Recuperação, Manutenção e Restauração de Edifícios. In: SEMINÁRIO INTERNACIONAL DA LARES LATIN AMERICA REAL ESTATE SOCIETY, 4., 2004, São Paulo. Anais... São Paulo, 2004. p. 421-428.

COSTA, D. C. B. Gestão Pós-Ocupação em Edifícios Reabilitados para Habitação de Interesse Social no Centro de São Paulo. 2009. Dissertação (Mestradoem Engenharia Civil) Escola Politécnica, Universidade de São Paulo, São Paulo, 2009.

DEVECCHI, A. M. Reformar Não É Construir: a reabilitação de edifícios verticais: novas formas de morar em São Paulo no século XX1. 2010. 547 f. Tese (Doutorado em Engenharia Civil) Faculdade de Arquitetura e Urbanismo, Universidade de São Paulo, São Paulo, 2010.

DIAS, P. R. V. Engenharia de Custos: uma metodologia de orçamentação para obras obras civis. 4. ed. Curitiba: Copiare. 2001. 213 p.

EGBU, C. O.; YOUNG, B. A.; TORRANCE, V. B. Planning and Control Processes and Techniques for Refurbishment Management. Construction Management and Economics, London, v. 16, p. 315-325, jul. 1997.

EUROCONSTRUCT CONFERENCE, 56., 2003, Madeira, Portugal. Anais... Madeira, 2003.

FLOURENTZOU, F.; GENRE, J. L.; ROULET, C. A. TOBUS Software: an interactive decision aid tool for building retrofit studies. Energy and Buildings, v. 34, n. 2, p. 193-202, 2002. 
FOREST, B. New Jersey Revs Up Its Rehabs. Planning, London, v. 65, n. 8, p. 10-16, ago. 1999.

FORMOSO, C. T. et al. Estimativa de Custos de Obras de Edificação. Porto Alegre: Universidade Federal do Rio Grande do Sul. 18 p. 1986.

Caderno Técnico do Curso de Pós-Graduação em Engenharia Civil.

GIAMMUSSO, S. E. Orçamento e Custos na Construção Civil. 2. ed. São Paulo: Pini, 1991. $181 \mathrm{p}$.

GOLDMAN, P. Introdução ao Planejamento e Controle de Custos na Construção Civil. 4. ed. atual. São Paulo: Pini, 2004. 176 p.

INTERNATIONAL CODE COUNCIL. International Existing Building Code. Illinois: CENGAGE Delmar Learning, 2003. 290 p.

JAGGS, M.; PALMER, J. Energy Performance Indoor Environmental Quality Retrofit: a european diagnosis and decision making method for building refurbishment. Energy and Buildings, v. 31, n. 2, p. 97-101, 2000

KERN, A. P.; FORMIGA, A. S.; FORMOSO, C. T. Considerações Sobre o Fluxo de Informações Entre os Setores de Orçamento e Produção em Empresas Construtoras. In: ENCONTRO NACIONAL DE TECNOLOGIA DO AMBIENTE CONSTRUÍDO, 10., 2004, São Paulo. Anais... São Paulo: Antac, 2004. p. 591601.

KERN, A. P.; FORMOSO, C. T. A Model for Integrating Cost Management and Production Planning and Control in Construction. Journal of Financial Management of Property and Construction, v. 11, n. 2, p. 75-90, ago. 2006.

LEEUWEN, J. P. van; VRIES, B. de; OETELAAR, E. van de. A Decision Support System for Building Refurbishment Design. In: INTERNATIONAL CONFERENCE ON CONSTRUCTION INFORMATION TECHNOLOGY, Reykjavik, 2000. Proceedings... Reykjavik, Islândia, 2000.

MANSFIELD, J. R. What's in a Name?: Complexities in the Definition of "Refurbishment". Property Management, Londres, v. 20, n. 1, p. 23-30, mar, 2002.

MARCHIORI, F. F.; SOUZA, U. E. L. de. Aprimoramento do Orçamento Convencional: a utilização do conceito de produtividade variável na atividade de alvenaria. In: CONGRESSO NACIONAL DA CONSTRUÇÃO, 2., Porto, 2004. Anais... Porto : FEUP, 2004. v. 1, p. 253 258.
MARICATO, E. Reabilitação de Centros Urbanos e a Habitação Social. In: SEMINÁRIO INTERNACIONAL GESTÃO DA TERRA URBANA E HABITAÇÃO DE INTERESSE SOCIAL, 2000, Campinas. Anais... Campinas: Pontifícia Universidade Católica de Campinas, 2000. 12 p.

MARQUES DE JESUS, C. R. Análise de Custos para Reabilitação de edifícios para Habitação. 2008. São Paulo. Dissertação (Mestrado em Engenharia Civil) - Escola Politécnica, Universidade de São Paulo, São Paulo, 2008.

MARQUES DE JESUS, C. R.; BARROS, M. M. S. B. Análise de Custos para Reabilitação de Edifícios Habitacionais. In: SIMPÓSIO BRASILEIRO DE GESTÃO E ECONOMIA DA CONSTRUÇÃO, 5., 2007, Campinas. Anais... Campinas, 2007. 10 p.

MUNHOZ, C. B. D., SOUZA, U. E. L. Análise da Produtividade em Reformas Residenciais Gerenciadas pelos Proprietário. In: SIMPÓSIO BRASILEIRO DE GESTÃO E ECONOMIA DA CONSTRUÇÃO, 6, 2009, João Pessoa. Anais... João Pessoa, 2009. 10 p.

PINI. Tabela de Composição de Preços para Orçamentos: TCPO 13. São Paulo, 13. ed. Pini, 2009.

PINI. Tabela de Custos de Manutenção e Reformas. São Paulo: Pini, 2006. 1 CD-ROM.

REABILITA. Diretrizes para Reabilitação de Edifícios para HIS: as experiências em São Paulo, Salvador e Rio de Janeiro, Projeto REABILITA. São Paulo: Escola Politécnica da Universidade de São Paulo, Universidade Católica de Salvador e Universidade Federal do Rio de Janeiro, 2007. 246 p.

SECRETARY of the Interior's Standards for Rehabilitation. Illustrated Guidelines for Rehabilitation Historic Buildings. Washington, 1992. Disponível em:

<http://www.cr.nps.gov/hps/tps/tax/rhb/index.htm >. Acesso em: 16 abr. 2006.

YOLLE NETO, José. Diretrizes para o Estudo de Viabilidade da Reabilitação de Edifícios Antigos na Região Central de São Paulo Visando a Produção de HIS: estudo de casos inseridos no Programa de Arrendamento Residencial (PAR-Reforma), edifícios Olga Bernário, Labor e Joaquim Carlos. 2006. Dissertação (Mestrado em Engenharia Civil) Escola Politécnica, Universidade de São Paulo, São Paulo, 2006. 
Revista Ambiente Construído

Associação Nacional de Tecnologia do Ambiente Construído

Av. Osvaldo Aranha, $99-3^{\circ}$ andar, Centro

Porto Alegre - RS - Brasil

CEP $90035-190$

Telefone: +55 (51) 3308-4084

Fax: +55 (51) 3308-4054

www.seer.ufrgs.br/ambienteconstruido

E-mail: ambienteconstruido@ufrgs.br

72 Jesus, C. R. M. de; Barros, M. M. S. B. de 